\title{
Resolving cavitary pneumonia presenting as late-onset congenital diaphragmatic hernia
}

\author{
Essam A. Elhalaby' ${ }^{1}$, Ronald B. Hirschl ${ }^{1}$, Alan Schlesinger ${ }^{2}$, and Arnold G. Coran ${ }^{1}$ \\ I Section of Pediatric Surgery, University of Michigan Medical School, C. S. Mott Children's Hospital, Ann Arbor, Michigan \\ 2 Section of Pediatric Radiology, C. S. Mott Children's Hospital and University of Michigan Medical School, Ann Arbor, Michigan
}

Accepted 16 November 1993

\begin{abstract}
An unusual case of resolving left lower lobe pneumonia associated with pleural effusion is reported. The plain radiographs and chest CT were initially misinterpreted as showing a late-presenting congenital diaphragmatic hernia $(\mathrm{CDH})$. This case illustrates that misleading radiologic assessments may occur in children with resolving pneumonia and that upper or lower gastrointestinal contrast studies should be a part of the diagnostic work-up of any case of suspected late-presenting $\mathrm{CDH}$.
\end{abstract}

Key words: Pneumonia - Congenital diaphragmatic hernia

\section{Introduction}

Considerable attention has been directed in the last few years toward the late presentation of congenital diaphragmatic hernia $(\mathrm{CDH})[1,2]$. The radiologic findings on plain chest radiograph in some children with staphylococcal pneumonia, lung abscess, and cystic bullae of the lung may be quite similar to those seen in cases of $\mathrm{CDH}$ [7]. In addition, many cases of late-presenting $\mathrm{CDH}$ have been initially misdiagnosed as pneumonia, pleural effusion, and pneumothorax [1, $2,5,9,10,13]$. Although the clinical course and general condition of children with staphylococcal pneumonia are often distinctive, it may be difficult to differentiate radiologically between a primary pulmonary disease process

Correspondence to: R. B. Hirschl, University of Michigan Pediatric Surgery Associates, L2110 Women's Hospital, Box 0245, Ann Arbor, MI 48109, USA

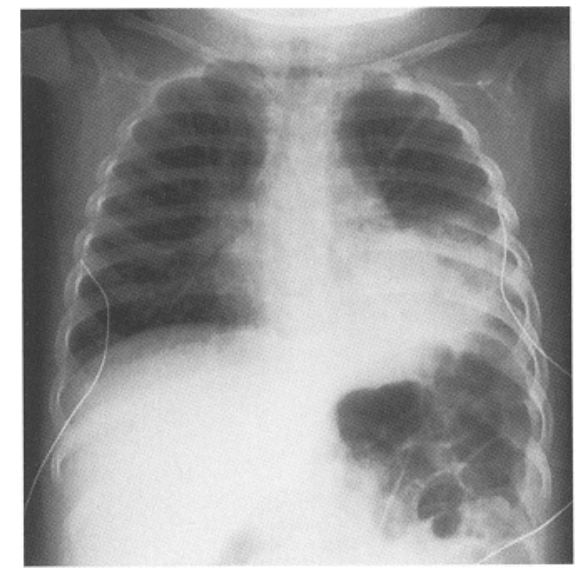

Fig. 1. Plain chest radiograph showing opacification in lower left chest cavity consistent with a left lower lobe pneumonia

and late-presenting $\mathrm{CDH}$. We present an unusual case of resolving cavitary staphylococcal pneumonia in which the radiographic findings were indistinguishable from a $\mathrm{CDH}$. The correct diagnosis was made after radiological evaluation with a gastrointestinal (GI) contrast study.

\section{Case report}

A 14-month-old girl presented at another institution with fever, cough, and tachypnea. A chest radiograph was consistent with a left lower lobe pneumonia (Fig. 1). A follow-up plain radiograph 12 days after the onset of the illness was interpreted as showing a case of late-presenting CDH (Fig. 2). Chest computed tomography (CT) was performed to exclude the possibility of an infected cystic adenomatoid malformation and was also interpreted as being consistent with a left CDH (Fig. 3 ). The patient was referred to the C. S. Mott Children's Hospital at the University of Michigan Medical Center for further evaluation and treatment.

On admission, the child was afebrile, comfortable, and did not appear septic. The

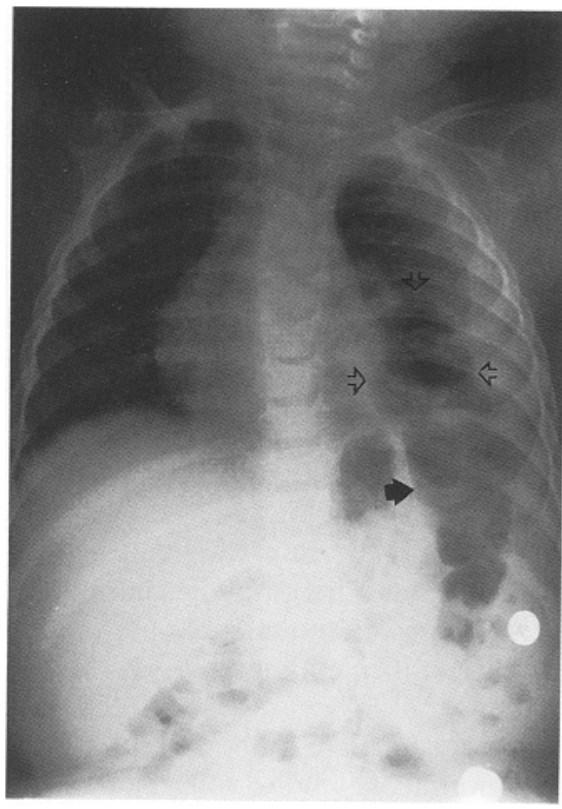

Fig. 2. Plain radiograph showing multiple lucent areas in left hemithorax (open arrows) in continuity with bowel gas observed in left upper abdomen and mild shift of trachea (arrowhead) and mediastinum toward right side

past medical history prior to the onset of pneumonia was noncontributory. Although repeat plain chest radiographs were consistent with a $\mathrm{CDH}$, an upper GI series with small-bowel follow-through revealed a normal position of the stomach, small intestine, and colon, with the simultaneous presence of the left lower lobe lucency observed on the plain chest radiograph, thereby excluding the diagnosis of a $\mathrm{CDH}$ (Fig. 4). Outpatient follow-up demonstrated gradual clearing of the radiologic findings with resolution of the pneumonia and pneumatocele.

\section{Discussion}

Approximately $10 \%-28 \%$ of all cases of $\mathrm{CDH}$ are diagnosed beyond the neonatal period $[2,14]$. Some authors 


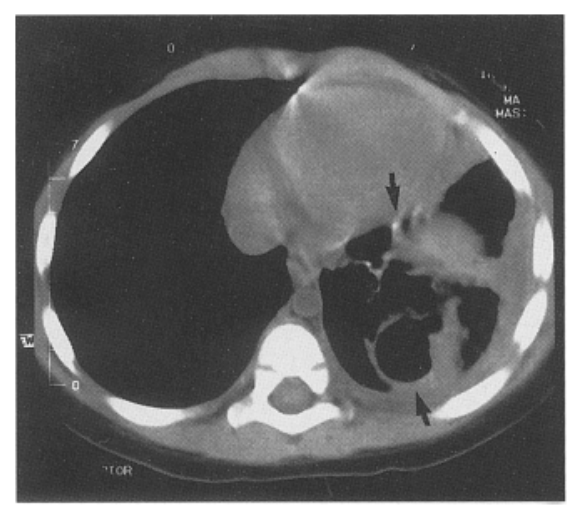

Fig. 3. Chest CT scan demonstrating multiple irregularly-shaped lucent areas, misinterpreted as a loop of bowel herniating into left hemithorax

[10] have recommended that the delayed presentation of $\mathrm{CDH}$ should be considered in the differential diagnosis in any patient with persistent vague GI or respiratory problems and an abnormal chest roentgenogram. The accuracy, however, of the plain radiograph in evaluating a suspected case of late-presenting $\mathrm{CDH}$ has been debated in the literature. Newman et al. [10] found that the diagnosis of $\mathrm{CDH}$ based on a plain chest roentgenogram was definitive enough to proceed to operation without further studies in only 3 of 11 cases. Bonham et al. [3], on the other hand, reported that plain radiographs were adequate in all but 1 of 66 cases. Although a normal position of the stomach does not exclude the presence of a C.DH, Berman et al. [2] found that the plain radiograph following the passage of a nasogastric tube was the test that best allowed differentiation of the diagnosis.

Various other imaging modalities have been proposed and utilized in the diagnosis of late-presenting $\mathrm{CDH}$, especially on the right side $[5,11,12]$. Pneumoperitoneography and contrast peritoneography have been used; these methods, however, are invasive and associated with the potential risk of complications. Real-time ultrasound is a noninvasive method that has been utilized to assess the integrity as well as the mobility of the diaphragm [11, 12]. Finally, radionuclide scans of the liver and spleen in addition to CT scans have been recommended as a diagnostic tool in cases of suspected late-presenting $\mathrm{CDH}$ [4]. However, a CT san was not helpful in reaching the correct diagnosis in the present case.

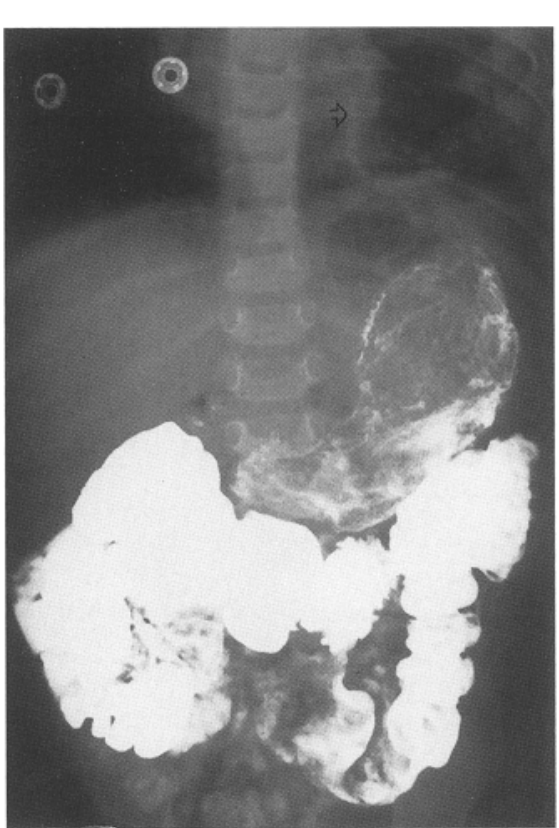

Fig. 4. Upper gastrointestinal contrast study showing normal position of stomach and intestine. Radiolucent areas in left lower hemithorax are still identifiable (open arrow), consistent with resolving cavitary pneumonia

The diagnosis of $\mathrm{CDH}$ in the reported case was ruled out by performing an upper GI study with smallbowel follow-through. Some authors $[6,8]$ claim that barium studies may underestimate the extent of the already present CDH due to spontaneous reduction in the erect position by the hydrostatic pressure of barium. Berman et al. [2] found that barium studies were considered helpful in the diagnosis of delayed-onset $\mathrm{CDH}$ in just under one-half of the studies performed. However, Newman et al. [10] concluded that contrast upper GI series or barium enemas were a necessary and accurate means of confirming the diagnosis of $\mathrm{CDH}$ in children with nonconclusive plain roentgenographs. Based on the findings in this case, we strongly agree with these conclusions, but would further suggest that a contrast GI study should be performed in all patients with suspected late-presenting $\mathrm{CDH}$ with respiratory symptoms to avoid a misdiagnosis in patients with cavitary pneumonia and radiographic findings consistent with a $\mathrm{CDH}$.

In summary, this case highlights the importance of contrast upper or lower GI studies in the evaluation of any case of suspected late-presenting $\mathrm{CDH}$ and draws attention to the radiologic findings observed in a child with resolving pneumonia, which may be similar to those seen in the patient with a late-presenting $\mathrm{CDH}$.

\section{References}

1. Ahmed S (1993) Incarcerated diaphragmatic hernia with gangrene and intestinal obstruction. Pediatr Surg Int 8: 144-145

2. Berman L, Stringer D, Ein SH, Shandling B (1988) The late presenting pediatric Bochdalek hernia: a 20-year review. J Pediatr Surg 23: 735-739

3. Bonham-Carter RE, Waterson DJ, Aberdeen E (1962) Hernia and eventration of the diaphragm in childhood. Lancet 1: $656-659$

4. Gale ME (1985) Bochdalek hernia: prevalence and CT characteristics. Radiology 156: $449-452$

5. Graviss ER, Danis RK, Lewis JE, Beach PJ, Silberstein MJ, Brodeur AE (1980) Peritoneography diagnosis of delayed onset right-sided diaphragmatic hernia masquerading as plural effusion. J Pediatr 97: $119-122$

6. Harrington SW (1963) Diaphragmatic hernia of children. Ann Surg 6: 301-315

7. Irving IM, Booker PD (1990) Congenital diaphragmatic hernia and eventration of the diaphragm. In: Lister J, Irving IM (eds) Neonatal surgery, 3rd edn. London, England, Butterworths, pp 199-220

8. Kirkland JA (1959) Congenital posterolateral diaphragmatic hernia in the adult. Br J Surg 47: 16-22

9. Leahy PF, Liu KW, Guiney EJ (1989) Pneumothorax - an unusual delayed presentation of congential posterolateral diaphragmatic hernia. Pediatr Surg Int 4: $415-416$

10. Newman BM, Afshani E, Karp MP, Jewet TC, Cooney DR (1986) Presentation of congenital diaphragmatic hernia past the neonatal period. Arch Surg 121: 813-816

11. Nussbaum AR, Ben-Ami $T$, Treves $S$, Teele RL (1987) Diagnosis of delayed onset right-sided congenital diaphragmatic hernia using ultrasonic and radionuclide imaging. Pediatr Surg Int 2: $149-156$

12. Poenaru D, Laberge JM, Jequier S, Blanchard PW, Doody DP (1988) Ultrasound diagnosis of delayed-onset congenital diaphragmatic hernia associated with group B streptococcal infection. Pediatr Surg Int 3: 66-69

13. Schmidt SP, Andrews HG, White JJ (1991) Silo-assisted closure of a late-presenting diaphragmatic hernia. Pediatr Surg Int 6: $357-358$

14. Snyder WH Jr, Greaney EM Jr (1965) Congenital diaphragmatic hernia; 77 consecutive cases. Surgery 57: 576-588 